\title{
MYOCARDIAL RESPONSES TO CHELATION
}

BY

\begin{abstract}
ALFRED SOFFER, TAFT TORIBARA, AND AKGUN SAYMAN
From the Department of Radiation Biology University of Rochester School of Medicine and Dentistry and the Cardiopulmonary Laboratories of the Rochester General Hospital, Rochester, New York, U.S.A.*
\end{abstract}

Received January 30, 1961

The phenomena of displacement and immobilization of calcium ions by chelation is being studied in an increasing number of clinical states. Chelation therapy in hypercalcæmia (Holland et al., 1953; Spencer et al., 1956), calcium deposition in coronary arteries (Meltzer et al., 1960) and peripheral vessels (Clarke et al., 1960) and in skin (Muller et al., 1959), and in the treatment of digitalis toxicity (Cohen et al., 1959) are under scrutiny and therefore careful analysis of the myocardial action of chelating drugs is warranted. In a 28-month study, 125 intravenous infusions of disodium ethylenediaminetetraacetate (disodium edathamil or EDTA) were administered to 58 subjects. Chelation produced four characteristic though occasionally variable responses of ventricular, atrial, and atrio-ventricular (A-V) junctional tissue: (1) suppression of ectopic ventricular beats and ventricular tachycardia, (2) slight slowing of the sino-atrial pacemaker, (3) improvement of A-V nodal conduction in first degree, second degree, and advanced heart block, and (4) increased automaticity of idioventricular pacemakers in complete heart block. Since the slowest effective rate of administration is the safest rate (Spencer et al., 1952), the total quantity of calcium chelated was determined for periods of administration varying from one-half to eleven hours.

\section{METHODS}

There were 58 subjects, 17 men and 41 women, with a mean age of 65 years. The arrhythmias present were ventricular premature contractions, 18 patients; atrial fibrillation, 11; complete heart block, 7; first-degree heart block, 6; ventricular tachycardia, 4; second degree heart block, 4; advanced heart block, 2; paroxysmal atrial tachycardia with block, 2; atrial flutter, 1 ; A-V dissociation with a nodal rate above 70,2 ; nodal rhythm with ventricular premature contractions and A-V dissociation, 1. Thirty-two patients had a basic sino-atrial pacemaker and 17 were in a state of digitalis intoxication. The disodium EDTA was given in dosages of from $0.5 \mathrm{~g}$. to $4 \mathrm{~g}$. in periods ranging from one-half hour to 11 hours. In three instances $3 \mathrm{~g}$. were administered in 30 minutes but in all other cases the rate of infusion never exceeded $4 \mathrm{~g}$. in 60 minutes. The drug was diluted in either 500 c.c. or 1000 c.c. of 5 per cent glucose in water. The concentration of the drug was maintained below 0.5 per cent unless congestive failure prohibited the use of dilute solutions. Ultrafiltrable serum calciums were determined by the method of Toribara and Terepka (Toribara et al., 1957). Samples deproteinized with trichloracetic acid were used for determining total serum calcium. Ashing with concentrated nitric acid was necessary to obtain complete recovery of chelated calcium.

* This paper is based in part on work performed under contract with the United States Atomic Energy Commission at the University of Rochester Atomic Energy Project, Rochester, New York. 


\section{Myocardial Responses to Chelation}

Ventricular Responses. Chelation therapy abolished or sharply diminished ventricular premature contractions in 12 out of 18 patients. This response was frequently as dramatic as that illustrated in Fig. 1. It was not dependent upon the presence of digitalis therapy. Chelation terminated ventricular tachycardia in 2 patients. One of these patients had digitalis intoxication. The other a 60-year-old woman with myocardial involvement due to myotonia dystrophica had never received digitalis. Two patients with ventricular tachycardia due to acute myocardial infarction showed no response to chelation therapy. In 6 patients with complete heart block, disodium EDTA increased the ventricular rate in every instance. This was accomplished without stimulation of other ventricular foci.

Sino-atrial Node and Atrial Responses. Chelation slowed the atrial pacemaker in 22 of 32 subjects. We feel that investigators who have reported sinus tachycardia as a manifestation of chelation (Bechtel et al., 1956; Surawicz et al., 1959) have produced toxic manifestations of hypocalcæmia due to a too rapid infusion of the chelating agent. Disodium EDTA slowed the ectopic atrial rate in two patients with atrial tachycardia with block due to digitalis intoxication.

$A-V$ Junctional Tissue Conductivity Responses. Disodium EDTA improved conduction in A-V junctional tissue in 6 of 12 patients with first degree, second degree, and advanced heart block. Two of the patients who responded had received no digitalis and three had digitalis intoxication. Representative responses are pictured in Fig. 2 and 3. In a patient with first-degree heart block there

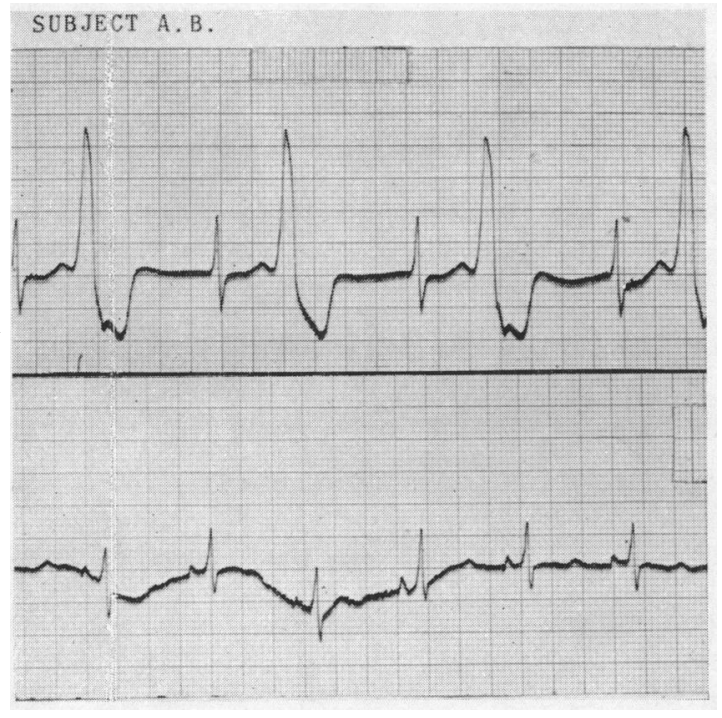

FIG. 1.-A-V dissociation with ventricular premature contractions following each nodal beat (above). Calcium chelation (EDTA 4g. in 1 hour) abolishes all ventricular ectopic rhythmicity and restores sinus rhythm (below).

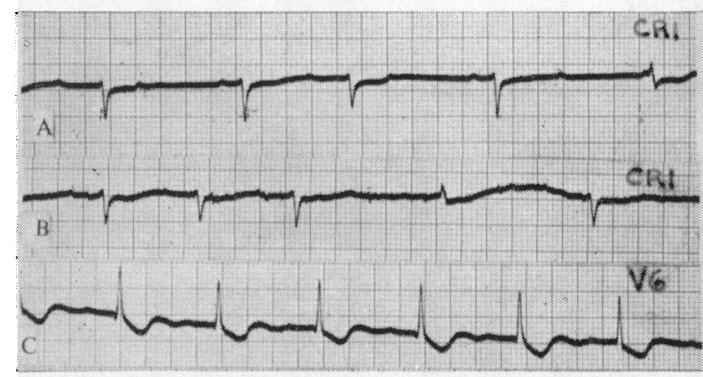

FIG. 2.-(A) Advanced heart block secondary to digitalis toxicity. (B) Twenty minutes after administration of disodium EDTA $2 \cdot 1 \mathrm{~g}$., improvement of conduction in A-V junctional tissue, and (C) $40 \mathrm{~min}$. later, conversion to sinus rhythm with first degree heart block.

was further depression of conduction through the A-V node, and in one instance second-degree heart block became complete heart block following therapy. There were two patients with paroxysmal atrial tachycardia with block due to digitalis intoxication. One of these, with incomplete A-V dissociation and double tachycardia (Fig. 3) responded to disodium EDTA with marked slowing of atrial and nodal pacemakers and the appearance of long runs of paroxysmal atrial tachycardia with 2-to-1 block. Occasional fusion complexes suggested the possibility of a preferential pathway for the nodal pacemaker. Intravenous potassium chloride produced a dominant rhythm of paroxysmal 


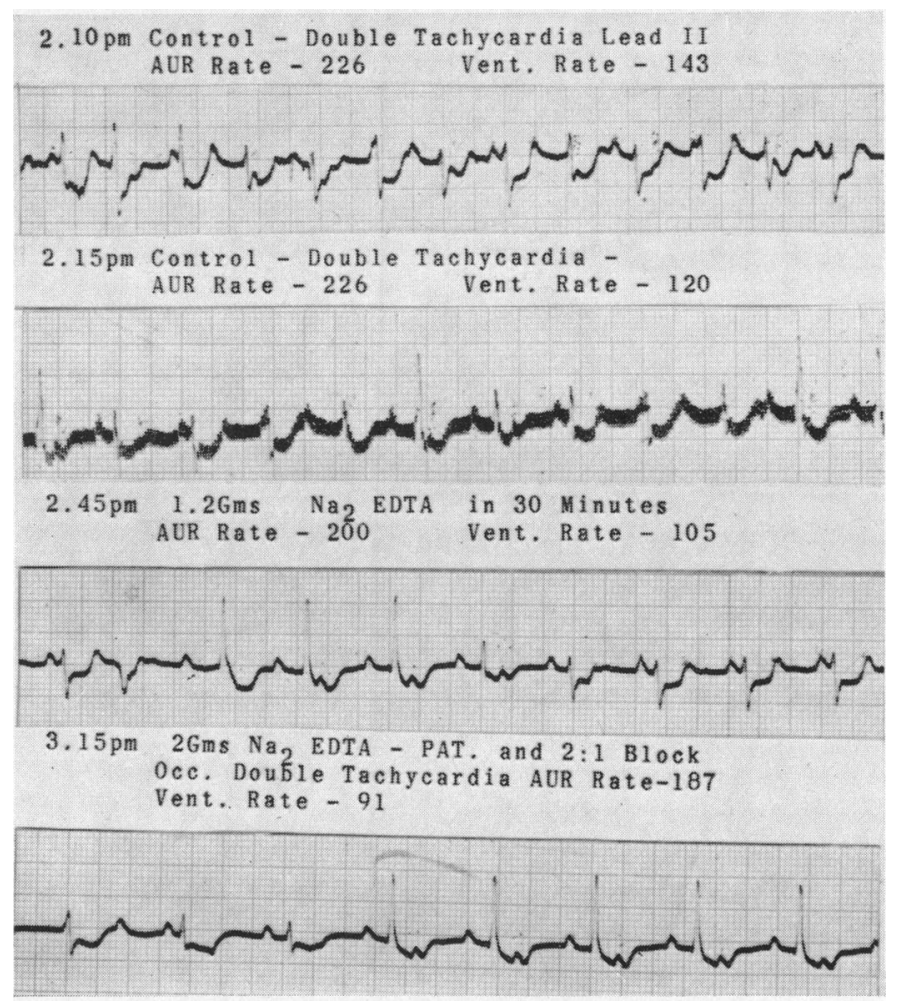

FIG. 3.-Digitalis toxicity with double tachycardia. Atrial tachycardia with a rate of 226 a minute is present in the two control tracings (AUR rate =atrial rate). A-V dissociation and A-V nodal tachycardia with slightly varying rate are also present. Disodium EDTA, 1.2 g., produces slowing of atrial and A-V nodal pacemakers (third strip) with occasional runs of atrial tachycardia with 2-to-1 block. The sixth beat is a fusion complex and suggests the possibility of a preferential pathway for the nodal pacemaker. In the last tracing the atrial and A-V nodal rates have been slowed by $2 \mathrm{~g}$. of disodium EDTA. Episodes of incomplete A-V dissociation alternate with long runs of atrial tachycardia (PAT) with 2-to-1 block.

atrial tachycardia and 2-to-1 block, later changing to sinus rhythm. The other patient with paroxysmal tachycardia with block showed only slight slowing of atrial and ventricular rates after therapy. Immediate conversion to sinus rhythm followed intravenous potassium chloride.

Nine of the 11 patients with atrial fibrillation, all receiving digitalis, responded to chelation with slight slowing of the ventricular rate. Potassium salts also possess the ability to depress A-V nodal conduction in auricular fibrillation and to enhance A-V nodal conduction in heart block (Bettinger et al., 1956; Fisch et al., 1958).

\section{Serum Calcium Ion Changes}

Chelating agents such as EDTA are presumed to act predominantly upon the ionic fraction of serum calcium. Electrocardiographic repolarization changes (prolongation of the Q-T interval) and an episode of tetany terminated by the infusion of calcium gluconate appeared to substantiate this theory. In order to verify experimentally these concepts, total ashed and ultrafiltrable serum calciums were determined before and after therapy in representative cases. A technique of wet 
ashing using concentrated nitric acid was devised. The results demonstrated that disodium EDTA does not change total serum calcium but rather chelation rearranges the distribution of calcium in the blood so that as the calcium chelate fraction rises, protein-bound and ionic calcium drop markedly (Soffer et al., 1960). Urinary losses of calcium are replaced from bone reservoirs. In representative cases, the average decrease in serum ionic calcium was $1.5 \mathrm{mg}$. per $100 \mathrm{ml}$. An effective degree of chelation was maintained in one patient for as long as 11 hours using a total of only $2.5 \mathrm{~g}$. of disodium EDTA.

\section{COMMENTS}

Chelation offers promise in the management of $A-V$ nodal conduction defects due to digitalis since it appears to enhance the rhythmicity of the idioventricular pacemaker while at the same time tending to improve, with occasional but important exceptions, the conductivity of A-V junctional tissue in advanced heart block. Experimental studies of the effect of serum calcium changes upon the myocardium are in conformity with these clinical observations. Brooks and associates (1955) state that hypocalcæmia results in a great increase in spontaneous rhythmicity not only of normal pacemakers but also of all parts of the atrium and ventricle. Moreover these investigators have noted that in the presence of a high serum calcium, A-V conduction is delayed because of augmented vagal activity. A number of studies have shown that disodium EDTA can suppress ventricular contractions and terminate digitalisinduced ventricular tachycardia (Brothers and Kabakow, 1957; Gubner and Kallman, 1957; Cohen et al., 1959; Surawicz et al., 1959). Our case of ventricular tachycardia secondary to myotonia dystrophica is perhaps the first recorded case of ventricular tachycardia not due to digitalis therapy successfully terminated by chelation. Disodium EDTA possesses the ability to reverse the electrocardiographic pattern of "digitalis effect" (Fig. 4). Contrary to earlier

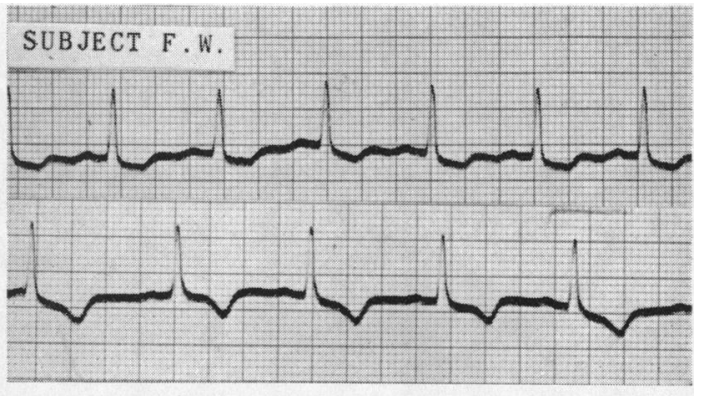

Fig. 4.-Loss of digitalis effect (spoon-shaped contour of S-T segments) induced by chelation (EDTA $4 \mathrm{~g}$. in $2 \mathrm{hr}$.). Above-before treatment, serum calcium $10 \cdot 2 \mathrm{mg}$. per $100 \mathrm{ml}$. Below-after treatment, serum calcium $8.4 \mathrm{mg}$. per $100 \mathrm{ml}$. judgements (Kabakow and Brothers, 1958; Jick and Karsh, 1959), the response of digitalis-induced arrhythmias and conduction abnormalities to EDTA can not be used for the diagnosis of digitalis toxicity because of the variable results.

Untoward reactions in our patients included orthostatic hypotension, circumoral paræsthesiæ, nausea, one instance of anæmia following repeated injections and one of hypocalcæmic convulsions. It appeared that a sharp rise in heart rate was the most important sign of impending crisis. To protect against side effects, the maximum daily dosage of EDTA, $50 \mathrm{mg}$. per kilogram, should ordinarily be given in a period of not less than one hour.

Serum hypocalcæmia induced by EDTA appears to have relatively predictable effects upon blood pressure, myocardial rhythmicity and conductivity. This knowledge permits greater understanding of the iatrogenic hypocalcæmia produced by transfusion with large amounts of citrated blood, a not uncommon occurrence in the surgical patient (Lown et al., 1960).

\section{SUMMARY}

Hypocalcæmia was induced in 58 subjects by the intravenous injection of from 0.5 to $4 \mathrm{~g}$. of the chelating agent, disodium EDTA. Chelation abolished ectopic ventricular beats, terminated ventricular tachycardia, and produced improvement of A-V nodal conduction in heart block. There were exceptions to these characteristic actions and this variability of responses prohibits the use of 
disodium EDTA in the diagnosis of digitalis toxicity. However, chelation offers promise in the short-term management of ventricular arrhythmias due to digitalis overdosage. Such therapy appears to be particularly indicated if these arrhythmias occur in the presence of impairment of A-V nodal conduction.

\section{REFERENCES}

Bechtel, J. T., White, J. E., and Estes, E. H. (1956). Circulation, 13, 837.

Bettinger, J. C., Surawicz, B., Bryfogle, J. W., Anderson, B. N., Jr., and Bellet, S. (1956). Amer. J. Med., $21,521$. Brooks, C. M., Hoffman, B. F., Suckling, E. E., and Orias, O. (1955). Excitability of the Heart. Grune and Stratton, New York, p. 298.

Brothers, M. J., and Kabakow, B. (1957). Circulation, 16, 864.

Clarke, N. E., Clarke, N. E., Jr., and Mosher, R. E. (1960). Amer. J. med. Sci., 239, 732.

Cohen, B. D., Spritz, N., Lubash, G. D., and Rubin, A. L. (1959). Circulation, 19, 918.

Fisch, C. Shields, J. P., Ridolfo, S. A., and Feigenbaum, H. (1958). Circulation, 18, 98.

Gubner, R. S., and Kallman, H. (1957). Amer. J. med. Sci., 234, 136.

Holland, J. F., Danielson, E., and Sahagian-Edwards, A. (1953). Proc. Soc. exp. Biol. N.Y., 84, 359.

Jick, S., and Karsh, R. (1959). Amer. J. Cardiol., 4, 287.

Kabakow, B., and Brothers, M. J. (1958). Arch. intern. Med., 101, 1029.

Katz, L. N., and Pick, A. (1956). Clinical Electrocardiography. Part I. The Arrhythmias. Lea and Febiger, Philadelphia, p. 536.

Lown, B., Black, H., and Moore, F. D. (1960). Amer. J. Cardiol., 6, 309.

Meltzer, L. E., Ural, M. E., and Kitchell, J. R. (1960). Metal Binding in Medicine. J. B. Lippincott Co. Philadelphia, p. 132.

Muller, S. A., Brunsting, L. A., and Winkelmann, R. K. (1959). A.M.A. Arch. Dermat., 80, 101.

Soffer, A., Toribara, T., Moore-Jones, D., and Weber, D. (1960). Arch. intern. Med., 106, 824.

Spencer, H. S., Greenberg, J., Berger, E., Perrone, M., and Laszlo, D. (1956). J. Lab. clin. Med., 47, 29.

Spencer, H., Vankinscott, V., Lewin, I., and Laszlo, D. (1952). J. clin. Invest., 31, 1023.

Surawicz, B., MacDonald, M. G., Kaljot, V., and Bettinger, J. C. (1959). Amer. Heart J., 58, 493.

Toribara, T. Y., Terepka, A. R., and Dewey, P. A. (1957). J. clin. Invest., 36, 738. 